\title{
Techno-Economic analysis of the Scale-Up process of Electrochemically-Assisted Soil Remediation
}

López-Vizcaíno, R. ., ${ }^{\text {, }}$, Yustres, A. ${ }^{a}$, Sáez, C. ${ }^{\mathrm{b}}$, Cañizares, P. ${ }^{\mathrm{b}}$, Asensio, L. ${ }^{\mathrm{a}}$, Navarro, V.. , Rodrigo, M.A. ${ }^{\mathrm{b}}$

${ }^{\mathrm{a} G e o e n v i r o n m e n t a l ~ G r o u p, ~ C i v i l ~ E n g i n e e r i n g ~ S c h o o l, ~ U n i v e r s i t y ~ o f ~ C a s t i l l a-L a ~ M a n c h a, ~}$ Avda. Camilo José Cela s/n, 13071 Ciudad Real, Spain

${ }^{\mathrm{b}}$ Department of Chemical Engineering, Faculty of Chemical Sciences \& Technologies, University of Castilla-La Mancha, Campus Universitario s/n, 13071 Ciudad Real, Spain

* Corresponding author: ruben.lopezvizcaino@uclm.es; r.lopezvizcaino@gmail.com, Geoenvironmental Group, Civil Engineering School, University of Castilla-La Mancha, Avda. Camilo José Cela s/n, 13071 Ciudad Real, Spain

DOI: $\underline{\text { https://doi.org/10.1016/j.jenvman.2018.10.084 }}$ 


\begin{abstract}
This work presents a techno-economic study of the scaling-up of the electrochemicallyassisted soil remediation (EASR) process of polluted soil. Four scales have been selected for the study: laboratory, bench, pilot and prototype, with a capacity of treating a volume of soil of $1 \times 10^{-4}, 2 \times 10^{-3}, 0.11$ and $21.76 \mathrm{~m}^{3}$, respectively. This study analyses the technical information produced by studies carried out at each scale, and informs about the fixed costs (construction of the electrokinetic remediation reactor, installation of auxiliary services and purchase of analytical equipment) and variable costs (start-up, operation and dismantling of the test) derived from running a test at each of the evaluated scales. The information discussed in based on the experience gained with many evaluations carried out over the last decade at these scales. This information can provide useful guidance for developing a scaling-up of the EASR for many researchers starting on the evaluation of this important environmental remediation technology.
\end{abstract}

\title{
KEYWORDS
}

Electrokinetic remediation; Polluted soil; Scale-up; Economic analysis 


\section{INTRODUCTION.}

Electrochemically-assisted soil remediation (EASR) processes are a very interesting set of technologies, capable to remediate low-hydraulic permeability soils polluted not only with inorganic contaminants but also with organic pollutants.

These technologies are based on the application of an electric potential gradient $(\mathrm{V} / \mathrm{m})$ that produces a low electric current (A) between electrodes especially positioned in the soil, being the placement selected very important to get highly-efficient processes (Risco et al., 2016c; Risco et al., 2016e; Risco et al., 2016f). The electric field favours the movement of fluids, ions and charged particles by different transport phenomena, namely electroosmosis, electromigration and electrophoresis, respectively (Acar, 1993; Acar et al., 1995; Alshawabkeh et al., 1999; Reddy and Cameselle, 2009; Virkutyte et al., 2002). All these processes are generically known as electrokinetic soil remediation (EKR) processes. They are the most important processes but not the only ones. Thus, in addition to EKR, soil heating by electric ohmic loses and different chemical (ion exchange, formation and re-dissolution of precipitates, etc,) and electrochemical processes (water oxidation and reduction, deposition of metals, etc.) develop simultaneously in the soil when it undergoes the application of an electric field. The smart coupling of all these mechanisms makes EASR a very versatile and efficient technology, which has been used for the decontamination of soils polluted with a great variety of compounds, including heavy metals (Ferrucci et al., 2016; Ottosen et al., 2001; Pamukcu et al., 2004; Pazos et al., 2008), polycyclic aromatic hydrocarbons (PAH) (Bocos et al., 2015; Hahladakis et al., 2014), polychlorinated biphenyls (PCB) (Gomes et al., 2015; Pedersen et al., 2017), pesticides and herbicides (Ribeiro et al., 2011; Ribeiro et al., 2005; Rodrigo et al., 2014; Vieira dos Santos et al., 2017), among many others. From a scientific point of view, such 
works have generated a great and very useful increase of the knowledge in the field. In addition, other researchers went one step further and studied the scale-up of the process (Gupta et al., 2012; Jeon et al., 2015; Kim et al., 2012; Lee et al., 2011). Very relevant scientific conclusions have been obtained in such studies. One of those conclusions was that scale-up studies cannot be bypassed to demonstrate the viability of an EASR process because otherwise conclusions drawn may be significantly wrong (Barba et al., 2018; López-Vizcaíno et al., 2017a, b).

In spite of that, nowadays, available information related to the scale-up of EASR processes is very scarce. The work presented in this manuscript aims to reduce this limitation, by discussing the technical aspects and the economic requirements of the scaleup of EASR, based on the experience acquired by the authors in the recent years, with the application of these technologies in different studies aimed to evaluate the remediation of soils polluted with PAH and pesticides. In those studies experimental setups of different scales that include lab, bench (Mena et al., 2016a; Mena et al., 2016b; Ramírez et al., 2015), pilot (Risco et al., 2016a; Risco et al., 2016b; Risco et al., 2015; Risco et al., 2016d; Risco et al., 2016e; Risco et al., 2016f) and prototype (López-Vizcaíno et al., 2016; López-Vizcaíno et al., 2017a, b) scales were used. This work presents not only an economic investment estimation of the assets but also an evaluation of the cost associated to all stages involved in start-up, operation and dismantling of EASR processes, giving also valuable information about the knowledge that can be obtained in each of them.

These studies have been carried out considering four experimental setups with different sizes to evaluate the effect of the scale in the time and economic requirements. The experimental configurations studied were a laboratory setup with a soil volume of 0.0001 $\mathrm{m}^{3}$, bench setup with a soil volume of $0.002 \mathrm{~m}^{3}$, pilot setup with a soil volume of $0.11 \mathrm{~m}^{3}$ 
and a prototype facility with a soil volume of $21.76 \mathrm{~m}^{3}$. This information can be much appreciated for the scientific community as it can provide guidance to develop a scaling of an EASR process of polluted soil.

\section{MATERIALS AND METHODS.}

Four different scales of experimental setups have been evaluated: laboratory, bench, pilot and prototype scale. Table 1 presents the main features of all facilities and Figure 1 shows a plan view, a section and a picture of each EASR reactor. More detailed information about the setup and details of the instrumentation used can be found elsewhere (López-

Vizcaíno et al., 2014a, b; López-Vizcaíno et al., 2016; López-Vizcaíno et al., 2017a, b;

Vieira dos Santos et al., 2017).

Table 1. Main features of facilities used in the EKR experiments.

\begin{tabular}{l|l|l|l|l}
\hline Dimensions & Laboratory & Bench & Pilot & Prototype \\
\hline EKR reactor (Length×width×depth $(\mathrm{cm}))$ & $15 \times 15 \times 5$ & $50 \times 10 \times 10$ & $70 \times 50 \times 50$ & $400 \times 400 \times 200$ \\
Soil $\left(\right.$ Volume $\left(\mathrm{m}^{3}\right) /$ dry mass $\left.(\mathrm{kg})\right)$ & $1 \times 10^{-4} / 0.13$ & $2 \times 10^{-3} / 2.6$ & $0.11 / 139.1$ & $21.76 / 25446.4$ \\
Electrodes geometry & Cylindrical & Prismatic & Cylindrical & Cylindrical \\
Electrode dimensions $(\mathrm{cm})$ & $\emptyset=1 /$ height=10 & $1 \times 10 \times 10$ & $\emptyset=1 /$ height=10 & $\emptyset=15 /$ height=100 \\
Number of electrodes & 2 & 2 & 6 & 6 \\
Electrolyte well volume $\left(\mathrm{m}^{3}\right)$ & $3 \times 10^{-4}$ & $3 \times 10^{-3}$ & $4 \times 10^{-2}$ & 6.9 \\
\hline Construction material of EKR reactor & Glass & Methacrylate & Methacrylate & Reinforced Concrete \\
\hline
\end{tabular}




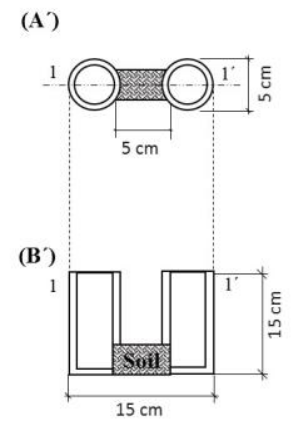

(C)

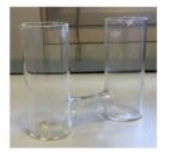

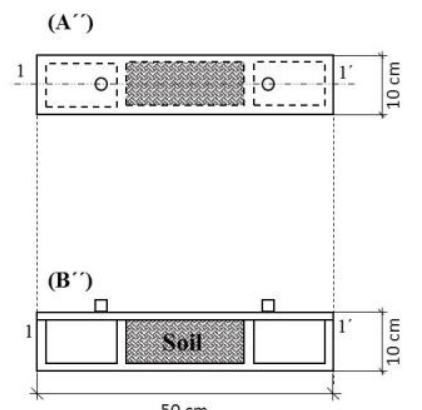

$50 \mathrm{~cm}$

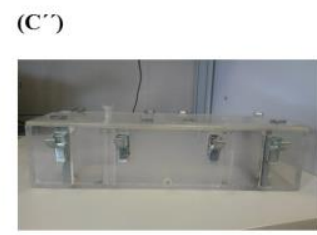

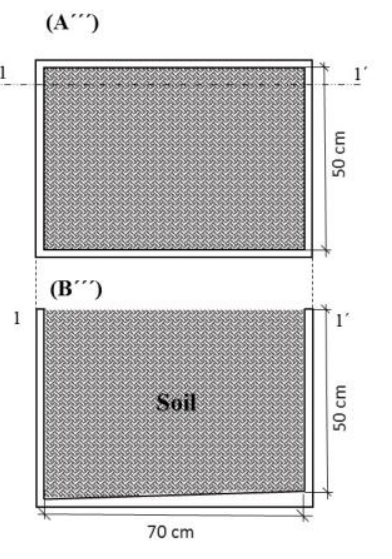

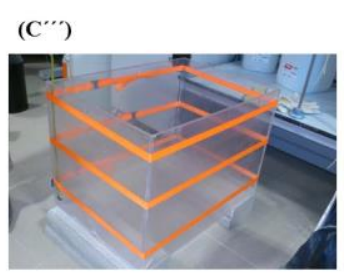

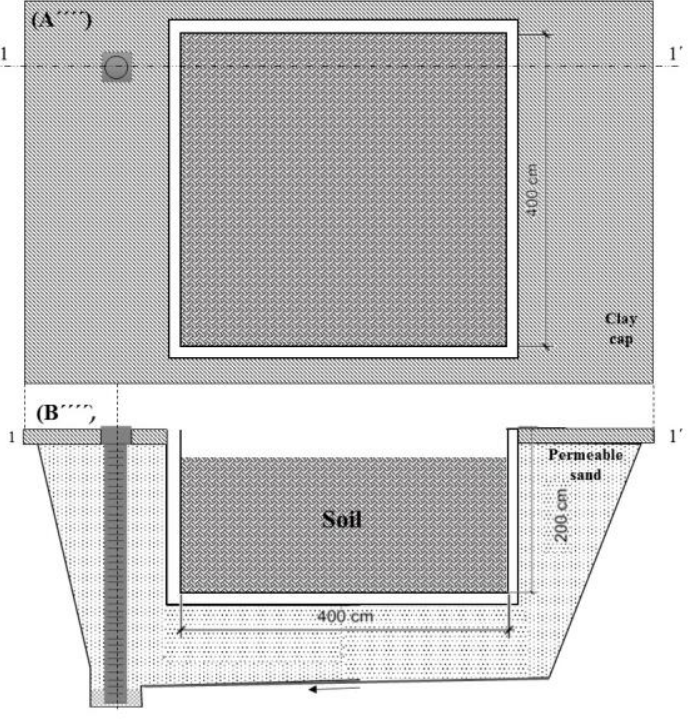

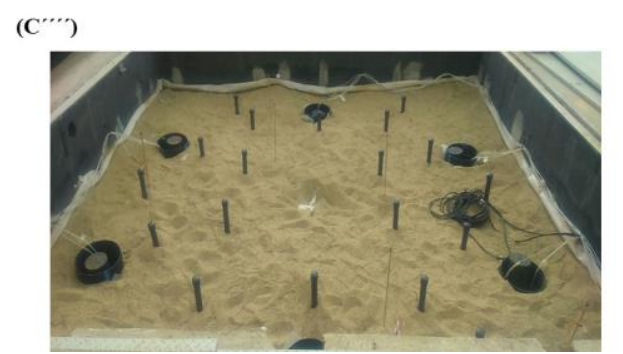

Figure 1. (A) Plan view, (B) 1-1'section and (C) Picture of the EASR reactors at (') laboratory scale, (") bench scale ("') pilot scale and ("'") prototype scale. 


\section{RESULTS AND DISCUSSION}

\subsection{Technical analysis}

Generally, in the fields of chemical and environmental engineering, the scaling-up of a process is divided into four steps: lab, bench, pilot and prototype (sometimes known as semi-industrial or even full-scale). Size increases in each scale-up step but, opposite to what it could be thought, it is not the key difference looked for. Thus, the studies carried out at each scale have a different purpose and when properly evaluated, they give a different piece of information. The connection between all these pieces of information leads to a complete understanding of the processes involved. Thus, each scale provides information that have to be used in the design of the next scale, so that all of them need to be performed to reach the final aim of a scale-up process: attain a total knowledge and control over the real scale process.

Bearing in mind the knowledge acquired in the intensive experimental campaigns carried out in our group over the last few years, the four scales were studied specifically for EASR processes and the main conclusion are summarized in a SWOT analysis shown in Figure 2. It marks the differences among the outcomes obtained in each of the scaling-up studies.

The aim in the lab-scale is to obtain a preliminary assessment of the technical feasibility of the process and an estimation of thermodynamic, transport and chemical kinetics parameters that can be used in mathematical models to design larger scales. The information obtained cannot be directly used to perform any type of extrapolation because all the processes are studied at extremely controlled conditions. Thus, because of the lower electric resistance associated to the smaller size, at this scale electrokinetic processes become more important than soil heating. Likewise, this lower resistance 
favours the production of higher current densities and hence reactivity processes are also promoted at this scale. Anyhow, a first estimation of electro-osmotic fluxes, diffusivity and electromigration parameters can be accurately obtained, as well as information regarding the ion exchange capacity of the soil and chemical and electrochemical reactivity.

The aim of the bench scale is to obtain mass and energy balances, and a complete initial understanding of the process (preliminary assessment of safety, waste generation and influence of feedstock). In addition, a previous assessment of the control and instrumentation needs can be performed in these studies. The larger size of the setups used in these studies leads to a decrease in the relative importance of the electrokinetic and reactive processes, although they are still the primary processes. Hence, very valuable information is obtained regarding the electro-osmotic fluxes and acidic and basic fronts, but it is still very weak to extrapolate it to full-scale. As in the lab-scale studies, information obtained is typically 1-D (associated to the main direction of change, which is the line between the electrodes of different polarity) but, despite of that, bench-scale evaluation starts to indicate that the parameters obtained at the lab-scale have to be handle very carefully in order to avoid wrong predictions.

In the pilot scale, the auxiliary services requirements are estimated, and typical operation problems and maintenance needs are evaluated. Here, the size of the setup is large enough to start showing the important differences between the electrokinetic and reactivity processes and the soil heating undergone by the soil. The higher resistance associated to the larger distance between electrodes starts to show that thermal processes are not negligible but the key processes in EASR. Configuration of electrodes starts to be one of the key inputs and in this scale, the 3-D configuration is started to be discerned as a key 
issue in scale-up because while some parameters scale-up linearly, others depend on surface and the rest on volume and an increase in one parameter may have an output raised to the two or to the three, depending on that issue.

Finally, in the prototype scale, the activities preliminary assessed in the pilot scale are defined in detail and it is obtained hands on experience in the operation and the ways to overcome real problems. The observations related to the primary mechanisms carried out in the pilot plant becomes much more important here and EKR becomes quite unimportant as compared to the soil heating. Although this stage is very important and even mandatory if sound conclusions have to be drawn, as it is going to be stated later in this manuscript, the huge experimental costs may discourage its use. 
Figure 2. SWOT analysis of the four evaluated EASR scales.

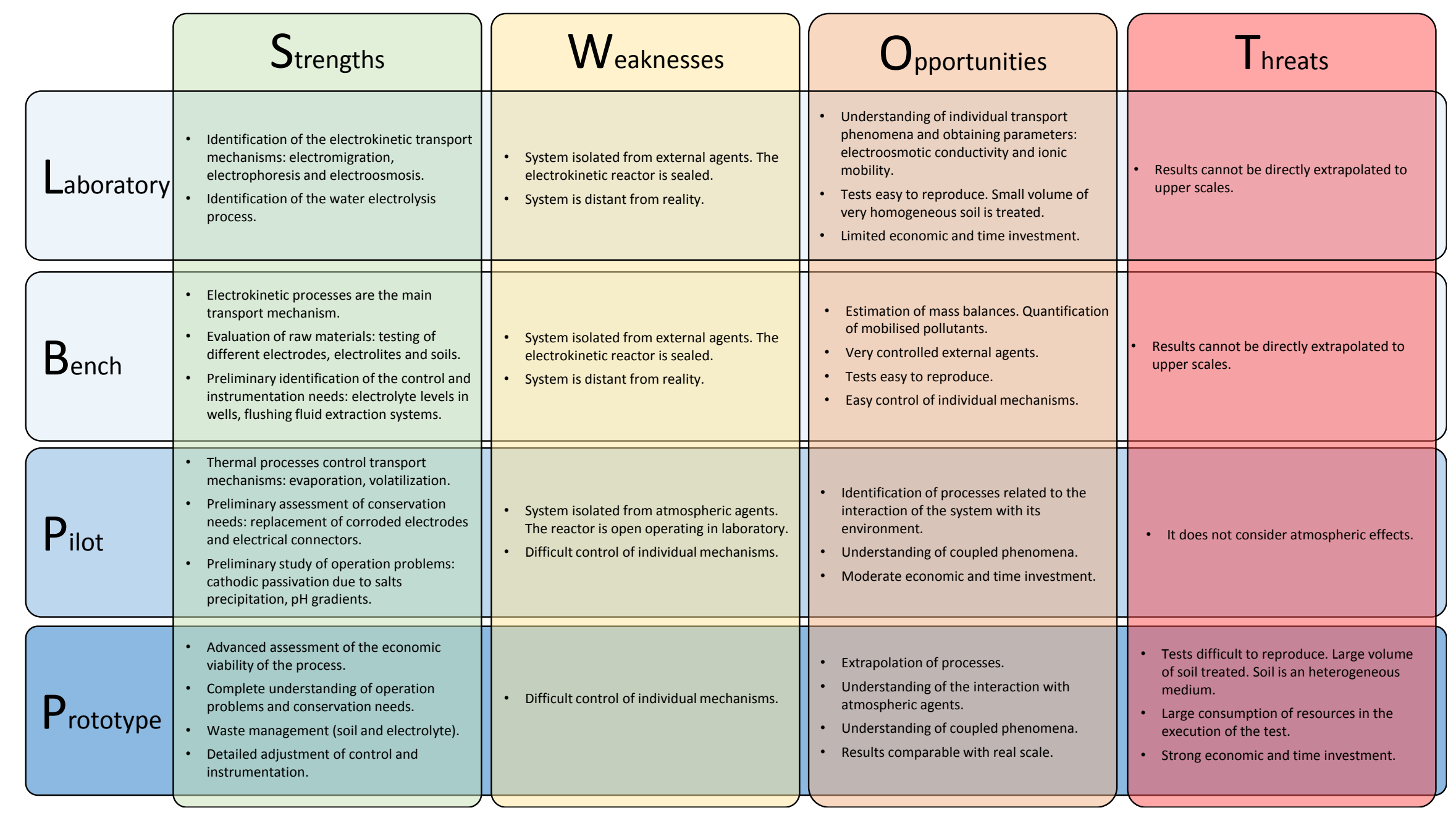




\subsection{Economic analysis}

Once the information that can be obtained from each of the four scales of the EASR process are defined, an economic analysis of each scale has been carried out. This analysis differentiates fixed and variable costs. As many different approaches can be taken, all data are presented as raw data. This means that by assuming the share use of equipment in other projects (in particular characterization equipment), a different cost figure can be obtained, but we have considered that for giving real valuable information these approaches should not be taken in this work.

\subsubsection{Fixed costs}

The fixed costs are composed by three different items: (i) costs derived from the construction of the electrokinetic reactor, (ii) costs of the analytical equipment (chromatography equipment, $\mathrm{pH}$, conductivity, temperature and water level meters), and (iii) auxiliary services (electric and hydraulic installations and related instrumentation, such as power supplies, pumps and compressors) (Figure 3). Table SM1 (Supplementary material) shows the detailed breakdown of the costs of these items.

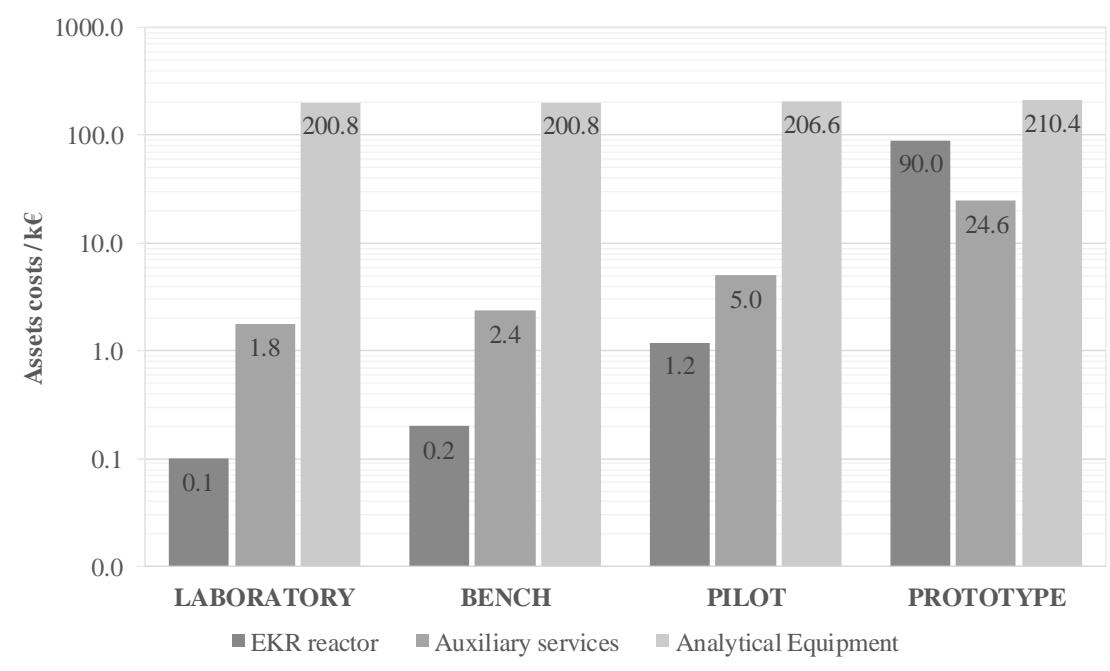

Figure 3. Economic contribution of each evaluated item to the fixed costs 
The costs of the construction of the electrokinetic reactor $(0.1-0.2 \mathrm{k} €)$ and those of the auxiliary services (about $2 \mathrm{k} €$ ) are of the same order of magnitude in the laboratory and bench scales. Both EKR reactors are of small dimensions (see Table 1 and Figure 1) and the main difference between them is their geometry. The auxiliary services needed to operate the installations are similar in both scales. The most significant difference in this respect is that the bench scale needs a more powerful power supply. In pilot and prototype scales, the increase of up-scaling is more relevant. The EASR pilot reactor costs approximately $1 \mathrm{k} €$, in contrast with the cost of $90 \mathrm{k} €$ of the prototype reactor. The pilot EASR reactor can be purchased directly from a methacrylate manufacturer; however, the cost of the prototype reactor includes the civil works needed for its construction. The most important differences in the costs of auxiliary services between pilot and prototype scales are derived from the power supply and the volatile retention system coupled in the prototype. The latter system becomes necessary in large scales, since the high temperatures reached in the tests favour the volatilisation of pollutants. This phenomenon and the volatile retention system were described in literature (López-Vizcaíno et al., $2017 \mathrm{a}, \mathrm{b})$. On the other hand, the change of scale does not significantly affect the cost of the analytical equipment, because the bulk of this item is common in all scales and corresponds to the ion chromatography and the high-performance liquid chromatography equipment (approximately $200 \mathrm{k} €$, depending on their detection system). The small differences between scales are due to different quantities of analytical sensors installed on site, which depend on the size of the installation: more sensors are needed in upper scales to keep a similar density of information and thus to obtain a representative sampling of the whole volume of treated soil. 


\subsubsection{Variable costs}

To estimate the total variable costs, the costs of labour, feedstock and analytical and auxiliary services have been included. These costs are assessed in three stages of the test: (i) start-up, (ii) operation and (iii) dismantling. Within the start-up stage, the activities developed can be grouped in the following substages:

- Substage i.1, Leakage control, including improving reactor waterproofing and characterisation tests of the EASR hydraulic behaviour.

- $\quad$ Substage i.2, Acquisition and soil preparation, including the materials used and transportation, as well as assembly and soil compaction.

- Substage i.3, Instrumentation of EKR reactor. Construction of the electrolyte wells and positioning of analytical equipment into the EASR reactors.

- Substage i.4, Start-up, including the soil saturation and pollutant spilling processes.

The detailed breakdown of the start-up (Table SM2) and operation and dismantling (Table SM3) costs is presented in the Supplementary Material.

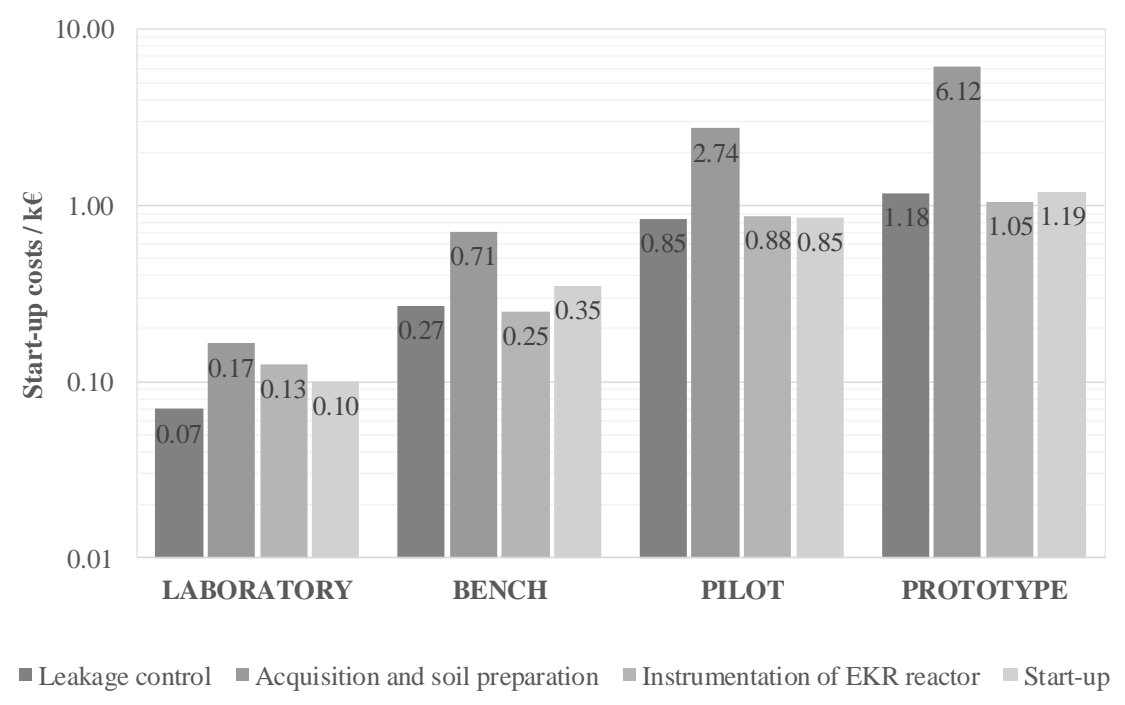

Figure 4. Economic contribution of the each substage to the start-up costs. 
Figure 4 shows the costs of the different substages composing the start-up stage of the test. The process of acquiring and preparing the soil is the costliest in the four stages evaluated, reaching a cost of $6.12 \mathrm{k} €$ in the prototype scale. In this scale, approximately an $80 \%$ of the costs of this substage correspond to labour and specialised machinery. The cost of this substage increases significantly with the up-scaling of the EASR process, because it is directly linked to the volume of treated soil. In the other evaluated substages (leakage control, instrumentation and start-up), the cost evolution does not increase steadily. These costs are of the same order of magnitude in laboratory and bench scales, although slightly larger in the latter. The same applies to pilot and prototype scales, with an approximate cost of $1 \mathrm{k} €$ per substage. The most significant differences are observed between bench and pilot scales, mainly because of an increase in the number of analytical tests required and in the instrumentation installed on site, and the consequent increase of the labour needed for their installation.

Figure 5 compares the variable costs of the start-up, operation and dismantling stages of the tests for the four scales. Both the start-up and the dismantling costs show a steady increase with the up-scaling. This is because the most important contribution to the costs in these stages is the labour required for the initial setup of the test and the dismantling of the final residue, which is proportional to the treated volume of soil. On the other hand, the costs of the operation of the EASR process increase from the laboratory to the pilot scale, but remain approximately constant at about $10 \mathrm{k} €$ from the pilot to the prototype scale. The last up-scaling step does not significantly increase the operation costs since they are determined by the number of analyses required (Table SM3), which is similar in the pilot and prototype scales. 


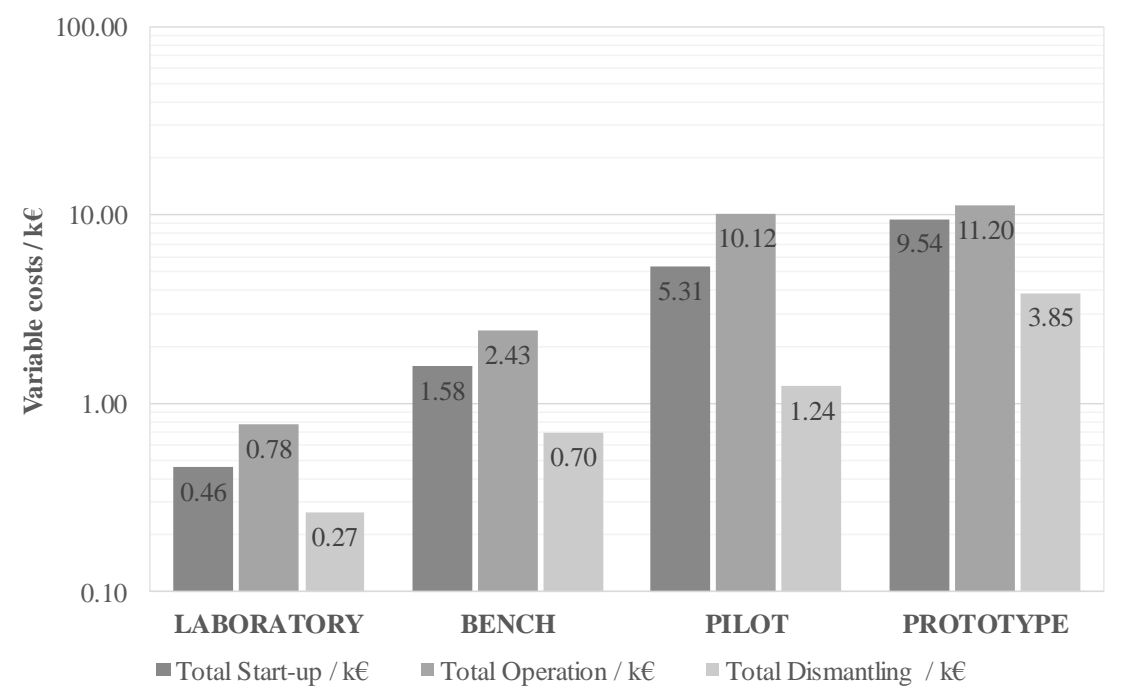

Figure 5. Economic contribution of each stage to the total variable costs.

\subsubsection{Summary of total costs}

To make it possible to compare the total costs corresponding to each scale, it is advisable to link the costs to a time unit. This work considers a time unit of one year. Two additional factors should be taken into account. First, an average amortisation period of the fixed capital should be defined. In this case, a linear amortisation in a five-year period has been considered. With this, the fixed costs per year can be estimated. In addition, the number of tests that can be performed in the time unit considered (a year in our case) must be defined. To this end, a Gantt chart has been produced for the four evaluated scales (Figure 6) which includes the time requirement of each stage (start-up, operation and dismantling). The chart shows that the time consumption at every stage is strongly determined by the scale of the study. Then, the number of tests that can be performed in a time unit depends on the selected scale. A maximum number of tests per year has been estimated for all scales: (i) 12 laboratory scale tests, (ii) 6 bench scale tests, (iii) 3 pilot scale tests, and (iv) 1 prototype scale test. With this information, it is possible to approximate the annual total costs for each scale as: 
Annual Total Cost $(k € /$ year $)=\frac{\text { Fixed costs }}{5 \text { years }}+\frac{N^{\circ} \text { test }}{1 \text { year }} \times \frac{\text { Variable costs }}{1 \text { test }}$

Once the annual total cost and the number of tests per year are known, the unitary total cost for each test at each studied scale can be obtained as:

Unitary Total Cost $(k € /$ test $)=\frac{1 \text { year }}{N^{0} \text { test }} \times \frac{\text { Fixed costs }}{5 \text { years }}+\frac{\text { Variable costs }}{1 \text { test }}$

Figure 7 compares annual variable, fixed and total costs, and unitary total costs, for the four test scales. 
Figure 6. Gantt diagram for the EASR tests that can be carried out in the four scales evaluated

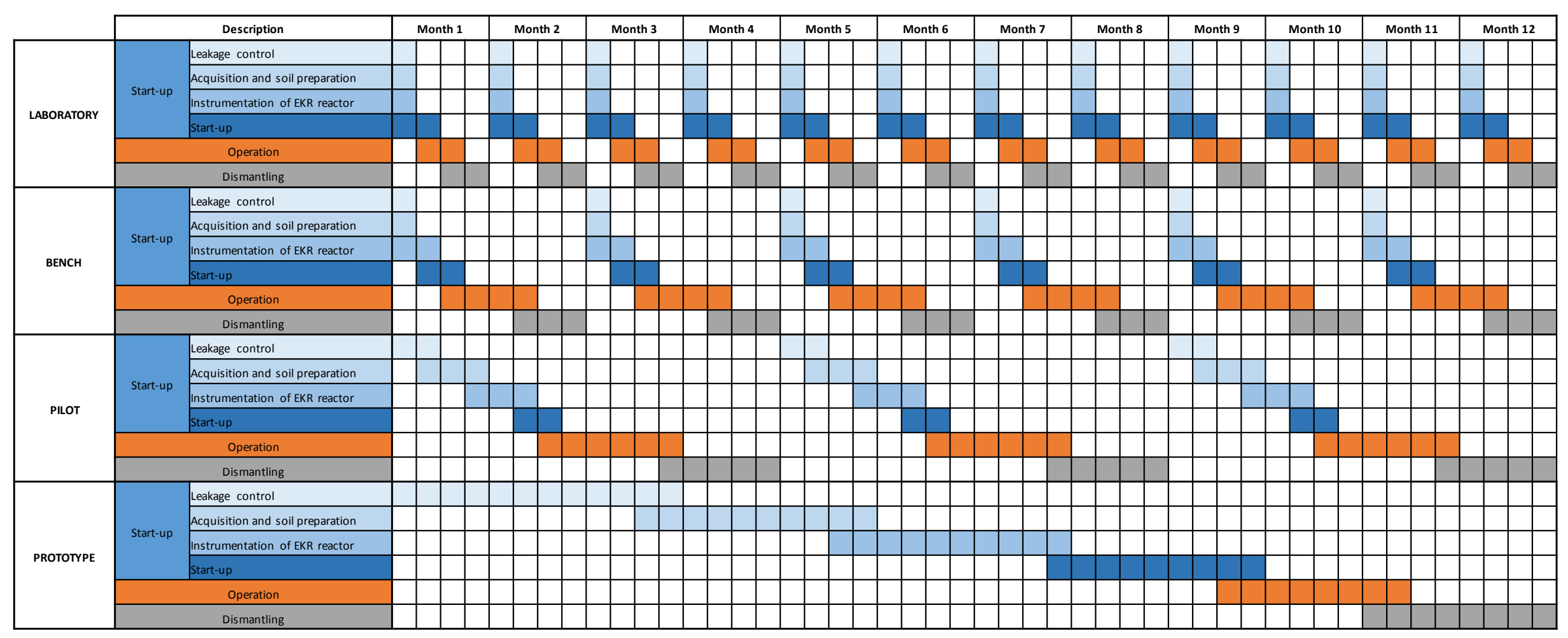




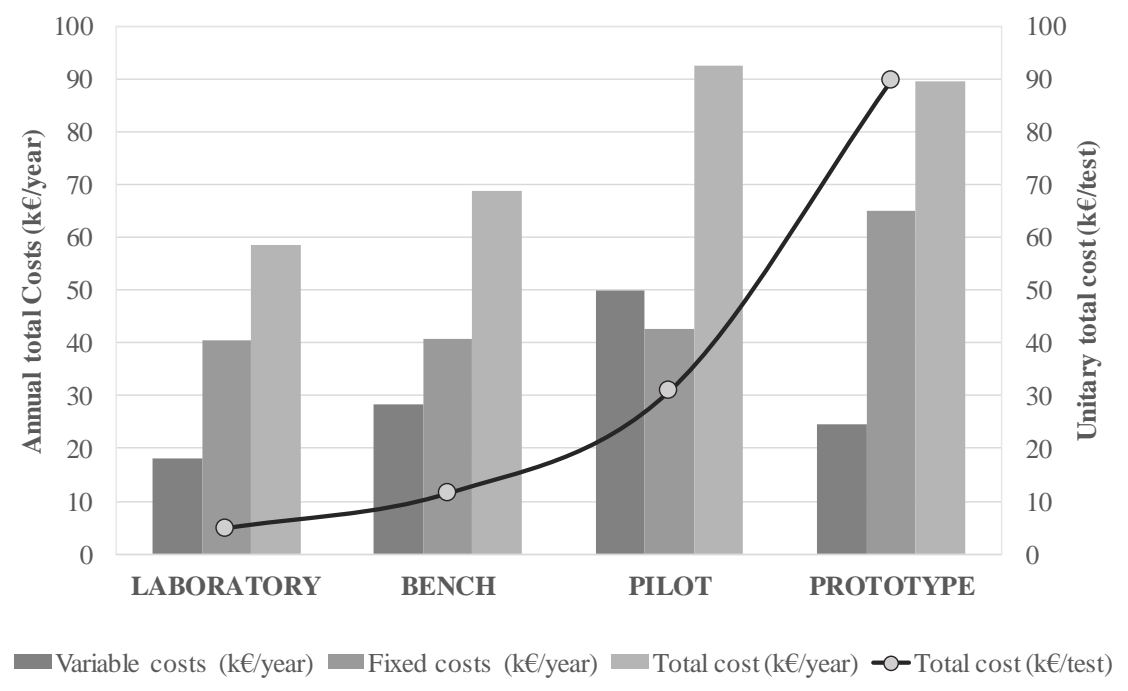

Figure 7. Comparative of annual variable, fixed and total costs and unitary total costs.

Figure 7 shows that the variable costs per year reach a maximum at the pilot scale (50 $k € /$ year). On the other hand, the fixed costs per year are similar in the laboratory, bench and pilot scales ( $40 € /$ year) but about a $50 \%$ greater in the prototype scale. These trends do not apply when analysing the unitary costs of each test. In that case, costs significantly increase with scale, from $5 \mathrm{k} €$ at laboratory scale up to $90 \mathrm{k} €$ in a prototype scale test.

Hence, taking into account the costs shown, from the viewpoint of a researcher, conducting research at very large scale can be a real problem and even cost-effective if it is taken into account the price of producing publishable results at large scale. However, as it was pointed out in the previous section, large scales cannot be overcome because they are giving the most important information required for the tuning of these systems for real applications.

\section{CONCLUSIONS}

The main conclusions of this work are: 
- In the scaling of an electrochemically-assisted soil remediation, the four studied scales (laboratory, bench, pilot and prototype) are necessary. Each scale contributes with pieces of relevant and non-overlapping information. Skipping any of the intermediate scales can lead to misinterpretation of the process, and consequently it can make difficult the design of upper scale tests.

- Laboratory and bench scales contribute information valuable to assess the technical feasibility of the EASR process. Pilot and prototype scales contribute information of use in the operation of the process. Soil heating is the most important process in full scale application although the smaller scales give much importance to electrokinetic processes. The SWOT table generated in this work can be useful for researchers in order to know the information that can be drawn at each stage.

- Fixed costs due to analytical equipment acquisition are similar in all the four scales analysed, since approximately the same instrumentation is needed regardless of the scale. The greatest differences in fixed costs are due to the construction of the electrokinetic remediation reactor, which reaches $90 \mathrm{k} €$ in the prototype scale (which involves civil works).

- Variable costs in the start-up and dismantling stages increase with scale, since they are proportional to the volume of soil treated. The operation costs are similar in the pilot and prototype scales, because they require a similar number of analysis.

- Assuming a linear amortisation in a five-year period of the fixed costs, and a capacity to perform 12 laboratory tests, 6 bench tests, 3 pilot tests or 1 prototype 
test in one year, the total cost per test at each scale are of 5, 10, 30 and $90 \mathrm{k} €$, respectively.

\section{SUPPLEMENTARY MATERIAL}

It includes a detailed breakdown of the fixed and variable costs of the items described in the body of the article for each of the four scales studied.

\section{ACKNOWLEDGEMENTS}

Financial support from the Spanish Ministry of Economy, Industry and Competitiveness and the European Union through project [CTM2016-76197-R (AEI/FEDER, UE)] and from Junta de Comunidades de Castilla - La Mancha through the Postdoctoral Grant [(SBPLY/16/180501/000402)] awarded to Dr. López-Vizcaíno are gratefully acknowledged. 


\section{REFERENCES}

Acar, Y.B., 1993. Principles of electrokinetic remediation. Environment Science Technology 27, 2638-2647.

Acar, Y.B., Gale, R.J., Alshawabkeh, A.N., Marks, R.E., Puppala, S., Bricka, M., Parker, R., 1995. Electrokinetic remediation: Basics and technology status. J. Hazard. Mater. 40, 117-137.

Alshawabkeh, A.N., Yeung, A.T., Bricka, M.R., 1999. Practical aspects of in-situ electrokinetic extraction. Journal of Environmental Engineering 125, 27-35.

Barba, S., Lopez-Vizcaino, R., Saez, C., Villasenor, J., Canizares, P., Navarro, V., Rodrigo, M.A., 2018. Electro-bioremediation at the prototype scale: What it should be learned for the scale-up. Chemical Engineering Journal 334, 2030-2038.

Bocos, E., Fernández-Costas, C., Pazos, M., Sanromán, M.Á., 2015. Removal of PAHs and pesticides from polluted soils by enhanced electrokinetic-Fenton treatment. Chemosphere 125, 168-174.

Ferrucci, A., Vocciante, M., Bagatin, R., Ferro, S., 2016. Electrokinetic remediation of soils contaminated by potentially toxic metals: Dedicated analytical tools for assessing the contamination baseline in a complex scenario. Journal of Environmental Management.

Gomes, H.I., Ottosen, L.M., Ribeiro, A.B., Dias-Ferreira, C., 2015. Treatment of a suspension of PCB contaminated soil using iron nanoparticles and electric current. Journal of Environmental Management 151, 550-555.

Gupta, M., Garg, N.K., Joshi, H., Sharma, M.P., 2012. Persistence and mobility of 2,4-D in unsaturated soil zone under winter wheat crop in sub-tropical region of India. Agriculture Ecosystems \& Environment 146, 60-72.

Hahladakis, J.N., Lekkas, N., Smponias, A., Gidarakos, E., 2014. Sequential application of chelating agents and innovative surfactants for the enhanced electroremediation of real sediments from toxic metals and PAHs. Chemosphere 105, 44-52.

Jeon, E.-K., Jung, J.-M., Kim, W.-S., Ko, S.-H., Baek, K., 2015. In situ electrokinetic remediation of As-, $\mathrm{Cu}$-, and $\mathrm{Pb}$-contaminated paddy soil using hexagonal electrode configuration: a full scale study. Environ. Sci. Pollut. Res. 22, 711-720.

Kim, D.-H., Jo, S.-U., Choi, J.-H., Yang, J.-S., Baek, K., 2012. Hexagonal two dimensional electrokinetic systems for restoration of saline agricultural lands: A pilot study. Chem. Eng. J. 198, 110-121.

Lee, Y.J., Choi, J.H., Lee, H.G., Ha, T.H., Bae, J.H., 2011. Pilot-scale study on in situ electrokinetic removal of nitrate from greenhouse soil. Separation and Purification Technology 79, 254-263.

López-Vizcaíno, R., Alonso, J., Cañizares, P., León, M.J., Navarro, V., Rodrigo, M.A., Sáez, C., 2014a. Electroremediation of a natural soil polluted with phenanthrene in a pilot plant. J. Hazard. Mater. 265, 142-150.

López-Vizcaíno, R., Alonso, J., Cañizares, P., León, M.J., Navarro, V., Rodrigo, M.A., Sáez, C., 2014b. Removal of phenanthrene from synthetic kaolin soils by eletrokinetic soil flushing. Separation and Purification Technology 132, 33-40.

López-Vizcaíno, R., Navarro, V., León, M.J., Risco, C., Rodrigo, M.A., Sáez, C., Cañizares, P., 2016. Scale-up on electrokinetic remediation: Engineering and technological parameters. J. Hazard. Mater. 315, 135-143.

López-Vizcaíno, R., Risco, C., Isidro, J., Rodrigo, S., Saez, C., Cañizares, P., Navarro, V., Rodrigo, M.A., 2017a. Scale-up of the electrokinetic fence technology for the removal 
of pesticides. Part I: Some notes about the transport of inorganic species. Chemosphere 166, 540-548.

López-Vizcaíno, R., Risco, C., Isidro, J., Rodrigo, S., Saez, C., Cañizares, P., Navarro, V., Rodrigo, M.A., 2017b. Scale-up of the electrokinetic fence technology for the removal of pesticides. Part II: Does size matter for removal of herbicides? Chemosphere 166, 549555.

Mena, E., Villaseñor, J., Cañizares, P., Rodrigo, M.A., 2016a. Influence of electric field on the remediation of polluted soil using a biobarrier assisted electro-bioremediation process. Electrochimica Acta 190, 294-304.

Mena, E., Villaseñor, J., Rodrigo, M.A., Cañizares, P., 2016b. Electrokinetic remediation of soil polluted with insoluble organics using biological permeable reactive barriers: Effect of periodic polarity reversal and voltage gradient. Chem. Eng. J. 299, 30-36.

Ottosen, L.M., Hansen, H.K., Ribeiro, A.B., Villumsen, A., 2001. Removal of Cu, Pb and $\mathrm{Zn}$ in an applied electric field in calcareous and non-calcareous soils. J. Hazard. Mater. 85, 291-299.

Pamukcu, S., Weeks, A., Wittle, J.K., 2004. Enhanced Reduction of Cr(VI) by Direct Electric Current in a Comminated Clay. Environmental Science and Technology 38, 1236-1241.

Pazos, M., Gouveia, S., Sanromán, M.A., Cameselle, C., 2008. Electromigration of Mn, $\mathrm{Fe}, \mathrm{Cu}$ and $\mathrm{Zn}$ with citric acid in contaminated clay. Journal of Environmental Science and Health - Part A Toxic/Hazardous Substances and Environmental Engineering 43, 823-831.

Pedersen, K.B., Lejon, T., Jensen, P.E., Ottosen, L.M., 2017. Simultaneous electrodialytic removal of PAH, PCB, TBT and heavy metals from sediments. Journal of Environmental Management 198, 192-202.

Ramírez, E.M., Camacho, J.V., Rodrigo, M.A., Cañizares, P., 2015. Combination of bioremediation and electrokinetics for the in-situ treatment of diesel polluted soil: A comparison of strategies. Sci. Total Environ. 533, 307-316.

Reddy, K.R., Cameselle, C., 2009. Electrochemical Remediation Technologies for Polluted Soils, Sediments and Groundwater. John Wiley and Sons.

Ribeiro, A.B., Mateus, E.P., Rodríguez-Maroto, J.M., 2011. Removal of organic contaminants from soils by an electrokinetic process: The case of molinate and bentazone. Experimental and modeling. Separation and Purification Technology 79, 193-203.

Ribeiro, A.B., Rodriguez-Maroto, J.M., Mateus, E.P., Gomes, H., 2005. Removal of organic contaminants from soils by an electrokinetic process: the case of atrazine. Experimental and modeling. Chemosphere 59, 1229-1239.

Risco, C., López-Vizcaíno, R., Sáez, C., Yustres, A., Cañizares, P., Navarro, V., Rodrigo, M.A., 2016a. Remediation of soils polluted with 2,4-D by electrokinetic soil flushing with facing rows of electrodes: A case study in a pilot plant. Chem. Eng. J. 285, 128-136.

Risco, C., Rodrigo, S., López-Vizcaíno, R., Sáez, C., Cañizares, P., Navarro, V., Rodrigo, M.A., 2016b. Electrokinetic flushing with surrounding electrode arrangements for the remediation of soils that are polluted with 2,4-D: A case study in a pilot plant. Sci. Total Environ. 545-546, 256-265.

Risco, C., Rodrigo, S., López-Vizcaíno, R., Yustres, A., Sáez, C., Cañizares, P., Navarro, V., Rodrigo, M.A., 2015. Electrochemically assisted fences for the electroremediation of 
soils polluted with 2,4-D: A case study in a pilot plant. Separation and Purification Technology 156, Part 2, 234-241.

Risco, C., Rodrigo, S., Lopez Vizcaino, R., Yustres, A., Saez, C., Canizares, P., Navarro, V., Rodrigo, M.A., 2016c. Removal of oxyfluorfen from spiked soils using electrokinetic soil flushing with linear rows of electrodes. Chemical Engineering Journal 294, 65-72.

Risco, C., Rodrigo, S., López Vizcaíno, R., Yustres, A., Saez, C., Cañizares, P., Navarro, V., Rodrigo, M.A., 2016d. Removal of oxyfluorfen from spiked soils using electrokinetic soil flushing with linear rows of electrodes. Chem. Eng. J. 294, 65-72.

Risco, C., Rubí-Juárez, H., Rodrigo, S., López-Vizcaíno, R., Saez, C., Cañizares, P., Barrera-Díaz, C., Navarro, V., Rodrigo, M.A., 2016e. Removal of oxyfluorfen from spiked soils using electrokinetic soil flushing with the surrounding arrangements of electrodes. Sci. Total Environ. 559, 94-102.

Risco, C., Rubí-Juárez, H., Rodrigo, S., López Vizcaíno, R., Saez, C., Cañizares, P., Barrera-Díaz, C., Navarro, V., Rodrigo, M.A., 2016f. Removal of oxyfluorfen from spiked soils using electrokinetic fences. Separation and Purification Technology 167, 5562.

Rodrigo, M.A., Oturan, N., Oturan, M.A., 2014. Electrochemically Assisted Remediation of Pesticides in Soils and Water: A Review. Chemical Reviews 114, 8720-8745.

Vieira dos Santos, E., Sáez, C., Cañizares, P., Martínez-Huitle, C.A., Rodrigo, M.A., 2017. Reversible electrokinetic adsorption barriers for the removal of atrazine and oxyfluorfen from spiked soils. J. Hazard. Mater. 322, 413-420.

Virkutyte, J., Sillanpaa, M., Latostenmaa, P., 2002. Electrokinetic soil remediation critical overview. Sci. Total Environ. 289, 97-121. 


\section{Supplementary Material}

\section{Techno-Economic analysis of the Scale-Up process of Electrochemically-Assisted Soil Remediation}

López-Vizcaíno, R. a, ${ }^{\text {, }}$ Yustres, A. a, Sáez, C. ${ }^{\text {, }}$ Cañizares, P. ${ }^{\text {b }, ~ A s e n s i o, ~ L . ~}{ }^{a}$, Navarro, V. ${ }^{\text {, }}$ Rodrigo, M.A. ${ }^{\mathrm{b}}$

${ }^{a}$ Geoenvironmental Group, Civil Engineering School, University of Castilla-La Mancha, Avda. Camilo José Cela s/n, 13071 Ciudad Real, Spain

${ }^{\mathrm{b}}$ Department of Chemical Engineering, Faculty of Chemical Sciences \& Technologies, University of Castilla-La Mancha, Campus Universitario s/n, 13071 Ciudad Real, Spain

* Corresponding author: $\underline{\text { ruben.lopezvizcaino@uclm.es; }}$ r.lopezvizcaino@gmail.com, Geoenvironmental Group, Civil Engineering School, University of Castilla-La Mancha, Avda. Camilo José Cela s/n, 13071 Ciudad Real, Spain 
Table SM1. Fixed costs breakdown.

Table SM1.1. Fixed costs breakdown. Laboratory scale.

\begin{tabular}{|c|c|c|c|c|c|}
\hline & Consignment & Item & Units & Cost (€/units) & Total cost $/ €$ \\
\hline \multirow{16}{*}{ LABORATORY } & \multirow{2}{*}{ EKR reactor } & Reactor & 1 & 100 & 100 \\
\hline & & Subtotal & & & 100 \\
\hline & \multirow{7}{*}{ Analytical Equipment } & HPLC & 1 & 100000 & 100000 \\
\hline & & Ion chromatograph & 1 & 100000 & 100000 \\
\hline & & Multiparametric analyser & 1 & 800 & 800 \\
\hline & & Thermocouples & 0 & 200 & 0 \\
\hline & & Water level sensors & 0 & 1200 & 0 \\
\hline & & Tensiometers & 0 & 600 & 0 \\
\hline & & Subtotal & & & 200800 \\
\hline & \multirow{9}{*}{ Auxiliary services } & Electric supply system & 1 & 50 & 50 \\
\hline & & Hydraulic supply system & 1 & 50 & 50 \\
\hline & & Power supply & 1 & 200 & 200 \\
\hline & & Electrodes & 2 & 50 & 100 \\
\hline & & Pumps & 2 & 600 & 1200 \\
\hline & & Volatile retention system & 0 & 0 & 0 \\
\hline & & Level control system & 2 & 80 & 160 \\
\hline Total & & SCADA & 0 & 0 & 0 \\
\hline $202660 €$ & & Subtotal & & & 1760 \\
\hline
\end{tabular}

Table SM1.2. Fixed costs breakdown. Bench scale.

\begin{tabular}{|c|c|c|c|c|c|}
\hline & Consignment & Item & Units & Cost (€/units) & Total cost $/ €$ \\
\hline \multirow{16}{*}{ BENCH } & \multirow{2}{*}{ EKR reactor } & Reactor & 1 & 200 & 200 \\
\hline & & Subtotal & & & 200 \\
\hline & \multirow{7}{*}{ Analytical Equipment } & HPLC & 1 & 100000 & 100000 \\
\hline & & Ion chromatograph & 1 & 100000 & 100000 \\
\hline & & Multiparametric analyser & 1 & 800 & 800 \\
\hline & & Thermocouples & 0 & 200 & 0 \\
\hline & & Water level sensors & 0 & 1200 & 0 \\
\hline & & Tensiometers & 0 & 600 & 0 \\
\hline & & Subtotal & & & 200800 \\
\hline & \multirow{9}{*}{ Auxiliary services } & Electric supply system & 1 & 100 & 100 \\
\hline & & Hydraulic supply system & 1 & 100 & 100 \\
\hline & & Power supply & 1 & 600 & 600 \\
\hline & & Electrodes & 2 & 100 & 200 \\
\hline & & Pumps & 2 & 600 & 1200 \\
\hline & & Volatile retention system & 0 & 0 & 0 \\
\hline & & Level control system & 2 & 80 & 160 \\
\hline Total & & SCADA & 0 & 0 & 0 \\
\hline $203360 €$ & & Subtotal & & & 2360 \\
\hline
\end{tabular}

Table SM1.3. Fixed costs breakdown. Pilot scale.

\begin{tabular}{|c|c|c|c|c|c|}
\hline & Consignment & Item & Units & Cost (€/units) & Total cost / $€$ \\
\hline \multirow{16}{*}{ PILOT } & \multirow{2}{*}{ EKR reactor } & Reactor & 1 & 1200 & 1200 \\
\hline & & \multicolumn{3}{|l|}{ Subtotal } & 1200 \\
\hline & \multirow{7}{*}{ Analytical Equipment } & HPLC & 1 & 100000 & 100000 \\
\hline & & Ion chromatograph & 1 & 100000 & 100000 \\
\hline & & Multiparametric analyser & 1 & 800 & 800 \\
\hline & & Thermocouples & 5 & 200 & 1000 \\
\hline & & Water level sensors & 0 & 1200 & 0 \\
\hline & & Tensiometers & 8 & 600 & 4800 \\
\hline & & \multicolumn{3}{|l|}{ Subtotal } & 206600 \\
\hline & \multirow{9}{*}{ Auxiliary services } & Electric supply system & 1 & 100 & 100 \\
\hline & & Hydraulic supply system & 1 & 100 & 100 \\
\hline & & Power supply & 1 & 2000 & 2000 \\
\hline & & Electrodes & 6 & 100 & 600 \\
\hline & & Pumps & 2 & 600 & 1200 \\
\hline & & Volatile retention system & 1 & 500 & 500 \\
\hline & & Level control system & 6 & 80 & 480 \\
\hline Total & & SCADA & 0 & 0 & 0 \\
\hline $212780 €$ & & Subtotal & & & 4980 \\
\hline
\end{tabular}


Table SM1.4. Fixed costs breakdown. Prototype scale.

\begin{tabular}{|c|c|c|c|c|c|}
\hline & Consignment & Item & Units & Cost (€/units) & Total cost $/ €$ \\
\hline \multirow{16}{*}{ PROTOTYPE } & \multirow{2}{*}{ EKR reactor } & Reactor & 1 & 90000 & 90000 \\
\hline & & Subtotal & & & 90000 \\
\hline & \multirow{7}{*}{ Analytical Equipment } & HPLC & 1 & 100000 & 100000 \\
\hline & & Ion chromatograph & 1 & 100000 & 100000 \\
\hline & & Multiparametric analyser & 1 & 800 & 800 \\
\hline & & Thermocouples & 6 & 200 & 1200 \\
\hline & & Water level sensors & 3 & 1200 & 3600 \\
\hline & & Tensiometers & 8 & 600 & 4800 \\
\hline & & Subtotal & & & 210400 \\
\hline & \multirow{9}{*}{ Auxiliary services } & Electric supply system & 1 & 1200 & 1200 \\
\hline & & Hydraulic supply system & 1 & 800 & 800 \\
\hline & & Power supply & 1 & 6000 & 6000 \\
\hline & & Electrodes & 6 & 300 & 1800 \\
\hline & & Pumps & 6 & 600 & 3600 \\
\hline & & Volatile retention system & 1 & 5000 & 5000 \\
\hline & & Level control system & 6 & 200 & 1200 \\
\hline Total & & SCADA & 1 & 5000 & 5000 \\
\hline $325000 €$ & & Subtotal & & & 24600 \\
\hline
\end{tabular}

Table SM2. Start-up costs breakdown.

Table SM2.1. Start-up costs breakdown. Laboratory scale.

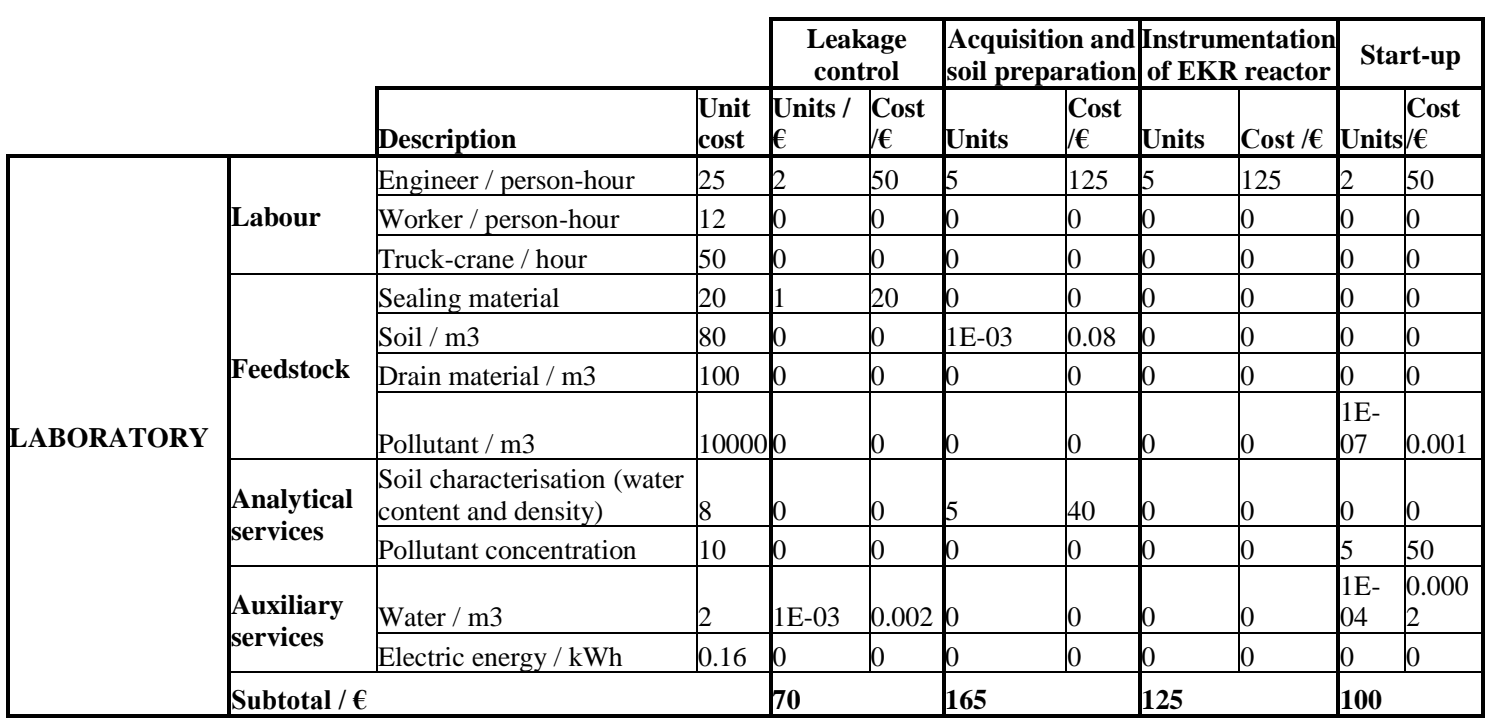

Table SM2.2. Start-up costs breakdown. Bench scale.

\begin{tabular}{|c|c|c|c|c|c|c|c|c|c|c|c|}
\hline & \multirow[b]{2}{*}{ Description } & \multirow[b]{2}{*}{$\begin{array}{l}\text { Unit } \\
\text { cost }\end{array}$} & \multicolumn{2}{|c|}{$\begin{array}{l}\text { Leakage } \\
\text { control }\end{array}$} & \multicolumn{2}{|c|}{$\begin{array}{l}\text { Acquisition and } \\
\text { soil preparation }\end{array}$} & \multicolumn{2}{|c|}{$\begin{array}{l}\text { Instrumentation } \\
\text { of EKR reactor } \\
\end{array}$} & \multicolumn{2}{|c|}{ Start-up } \\
\hline & & & & $\begin{array}{l}\text { Units / } \\
€\end{array}$ & $\begin{array}{l}\text { Cost } \\
/ €\end{array}$ & Units & Cost /€ & Units & Cost $/ €$ & Units & Cost /€ \\
\hline \multirow{12}{*}{ BENCH } & \multirow{3}{*}{ Labour } & Engineer / person-hour & 25 & 10 & 250 & 25 & 625 & 10 & 250 & 10 & 250 \\
\hline & & Worker / person-hour & 12 & 0 & 0 & 0 & 0 & 0 & 0 & 0 & 0 \\
\hline & & Truck crane-hour & 50 & 0 & 0 & 0 & 0 & 0 & 0 & 0 & 0 \\
\hline & \multirow{4}{*}{ Feedstock } & Sealing material & 20 & 1 & 20 & 0 & 0 & 0 & 0 & 0 & 0 \\
\hline & & Soil / m3 & 80 & 0 & 0 & 0.02 & 1.6 & 0 & 0 & 0 & 0 \\
\hline & & Drain material / m3 & 100 & 0 & 0 & 0 & 0 & 0 & 0 & 0 & 0 \\
\hline & & Pollutant / m3 & 10000 & 0 & 0 & 0 & 0 & 0 & 0 & $5 \mathrm{E}-06$ & 0.05 \\
\hline & \multirow{2}{*}{$\begin{array}{l}\text { Analytical } \\
\text { services }\end{array}$} & $\begin{array}{l}\text { Soil characterisation (water } \\
\text { content and density) }\end{array}$ & 8 & 0 & 0 & 10 & 80 & 0 & 0 & 0 & 0 \\
\hline & & Pollutant concentration & 10 & 0 & 0 & 0 & 0 & 0 & 0 & 10 & 100 \\
\hline & \multirow{2}{*}{\begin{tabular}{|l} 
Auxiliary \\
services
\end{tabular}} & Water / m3 & 2 & 0.02 & 0.04 & 0 & 0 & 0 & 0 & 0.002 & 0.004 \\
\hline & & Electric energy / kWh & 0.16 & 0 & 0 & 0 & 0 & 0 & 0 & 0 & 0 \\
\hline & \multicolumn{2}{|l|}{ Subtotal / € } & & \multicolumn{2}{|l|}{270} & \multicolumn{2}{|l|}{707} & \multicolumn{2}{|l|}{250} & \multicolumn{2}{|l|}{350} \\
\hline
\end{tabular}


Table SM2.3. Start-up costs breakdown. Pilot scale.

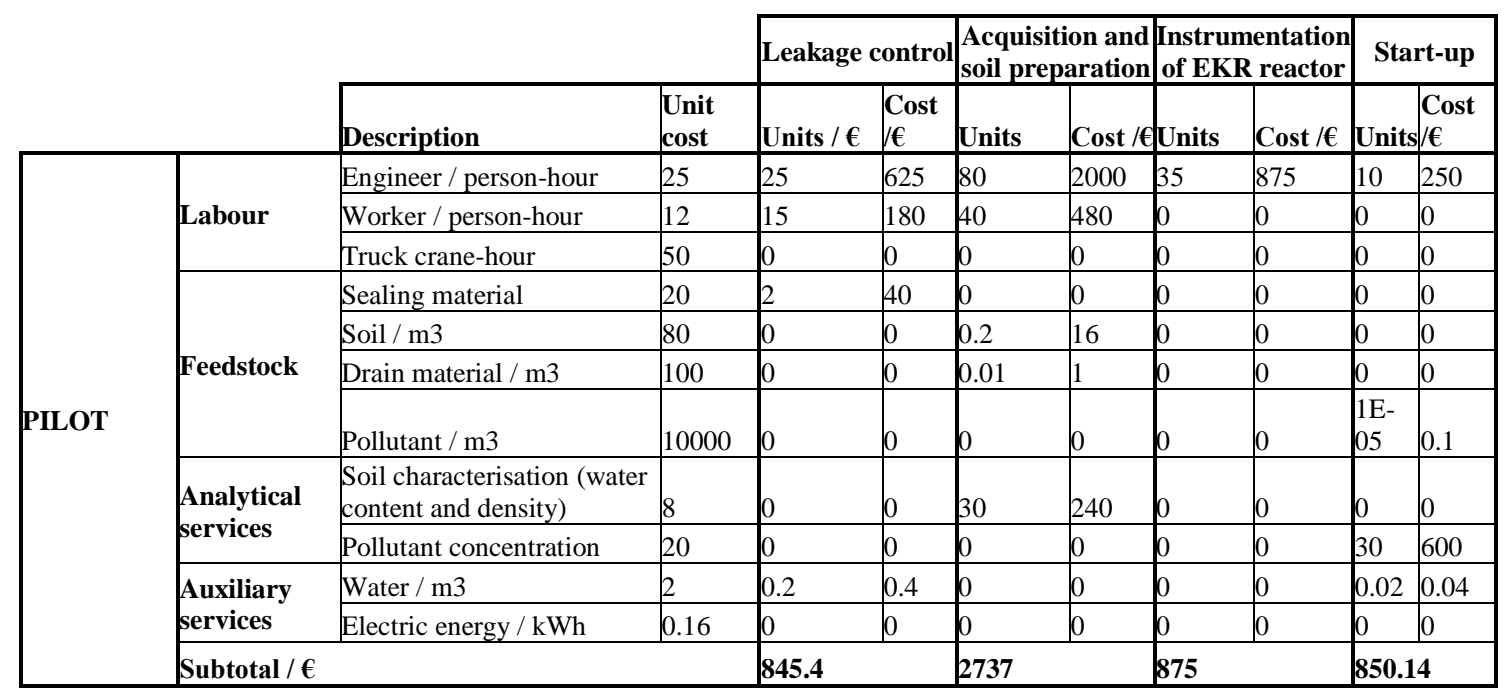

Table SM2.4. Start-up costs breakdown. Prototype scale.

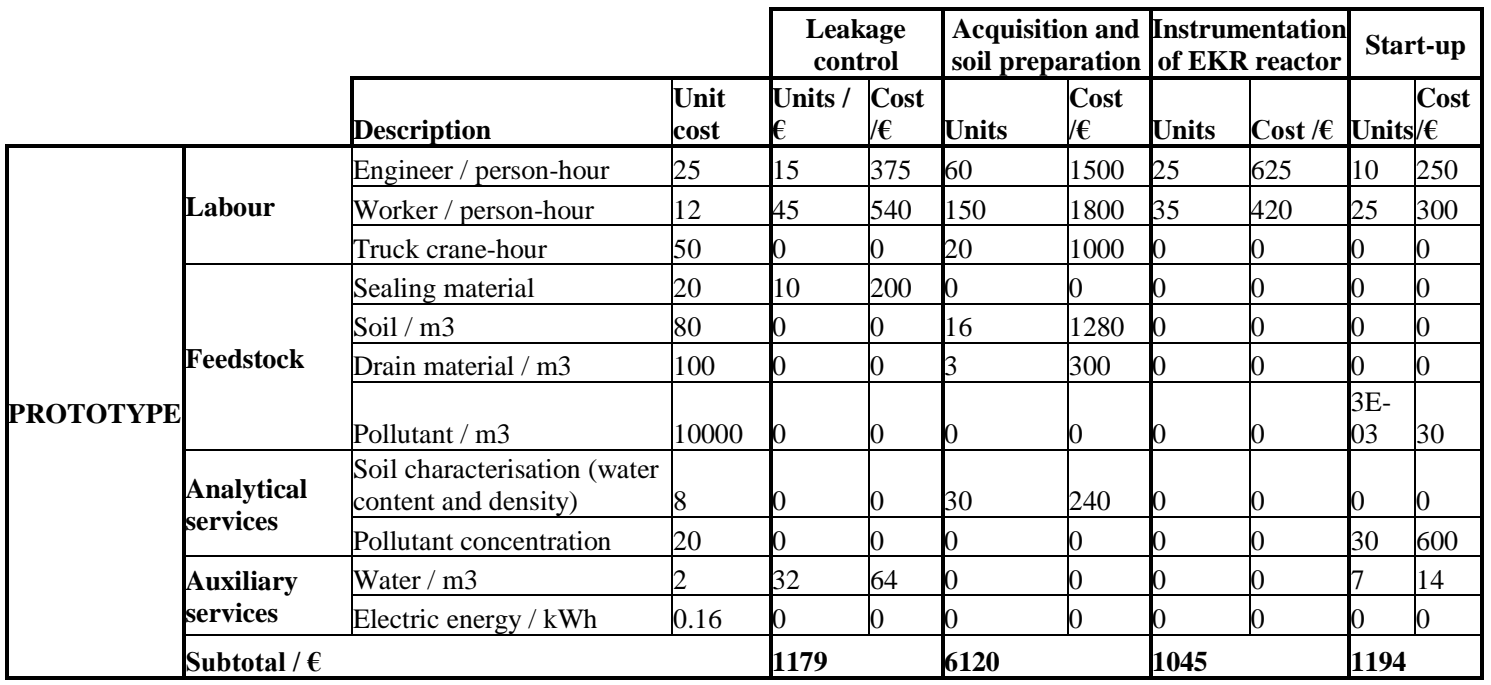

Table SM3. Operation and dismantling costs breakdown.

Table SM3.1. Operation and dismantling costs breakdown. Laboratory scale.

\begin{tabular}{|c|c|c|c|c|c|c|c|}
\hline & & & \multicolumn{2}{|c|}{ Operation } & \multicolumn{2}{|c|}{ Dismantling } \\
\hline & & Description & Unit cost $/ €$ & Units & Cost $/ €$ & Units & Cost $/ €$ \\
\hline \multirow{9}{*}{ LABORATORY } & \multirow{3}{*}{ Labour } & Engineer / person-hour & 25 & 15 & 375 & 5 & 125 \\
\hline & & Worker / person-hour & 12 & 0 & 0 & 0 & 0 \\
\hline & & Truck crane-hour & 50 & 0 & 0 & 0 & 0 \\
\hline & \multirow{2}{*}{$\begin{array}{l}\text { Analytical } \\
\text { services }\end{array}$} & $\begin{array}{l}\text { Soil characterisation (water } \\
\text { content and density) }\end{array}$ & 8 & 0 & 0 & 5 & 40 \\
\hline & & Pollutant concentration analysis & 20 & 20 & 400 & 5 & 100 \\
\hline & \multirow{3}{*}{$\begin{array}{l}\text { Auxiliary } \\
\text { services }\end{array}$} & Water / m3 & 2 & 0.002 & 0.004 & 0.001 & 0.002 \\
\hline & & Electric energy / kWh & 0.16 & 0.0504 & 0.008064 & 0 & 0 \\
\hline & & Waste management / Tm & 90 & 0 & 0 & 0.001 & 0.09 \\
\hline & \multicolumn{3}{|c|}{ Sub-total / $€$} & \multicolumn{2}{|c|}{775} & \multicolumn{2}{|c|}{265} \\
\hline
\end{tabular}


Table SM3.2. Operation and dismantling costs breakdown. Bench scale.

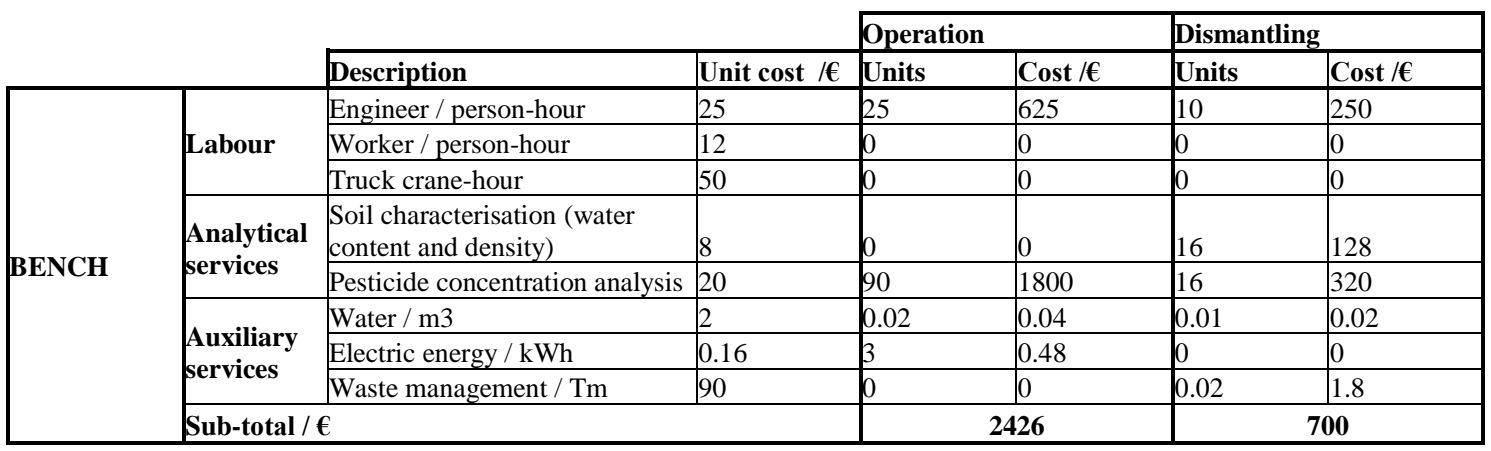

Table SM3.3. Operation and dismantling costs breakdown. Pilot scale.

\begin{tabular}{|c|c|c|c|c|c|c|c|}
\hline & \multirow[b]{3}{*}{ Description } & \multirow[b]{3}{*}{ Unit cost $/ €$} & & & & \\
\hline & & & & \multicolumn{2}{|c|}{ Operation } & \multicolumn{2}{|c|}{ Dismantling } \\
\hline & & & & Units & Cost $/ €$ & Units & $\operatorname{Cost} / €$ \\
\hline \multirow{9}{*}{ PILOT } & \multirow{3}{*}{ Labour } & Engineer / person-hour & 25 & 30 & 750 & 15 & 375 \\
\hline & & Worker / person-hour & 12 & 30 & 360 & 0 & 0 \\
\hline & & Truck crane-hour & 50 & 0 & 0 & 0 & 0 \\
\hline & \multirow{2}{*}{$\begin{array}{l}\text { Analytical } \\
\text { services }\end{array}$} & $\begin{array}{l}\text { Soil characterisation (water } \\
\text { content and density) }\end{array}$ & 8 & 0 & 0 & 30 & 240 \\
\hline & & Pesticide concentration analysis & 20 & 450 & 9000 & 30 & 600 \\
\hline & \multirow{3}{*}{$\begin{array}{l}\text { Auxiliary } \\
\text { services }\end{array}$} & Water / m3 & 2 & 0.2 & 0.4 & 1 & 2 \\
\hline & & Electric energy / kWh & 0.16 & 60 & 9.6 & 0 & 0 \\
\hline & & Waste management / Tm & 90 & 0 & 0 & 0.21 & 18.9 \\
\hline & \multicolumn{3}{|c|}{ Sub-total / € } & \multicolumn{2}{|c|}{10120} & \multicolumn{2}{|c|}{1236} \\
\hline
\end{tabular}

Table SM3.4. Operation and dismantling costs breakdown. Prototype scale.

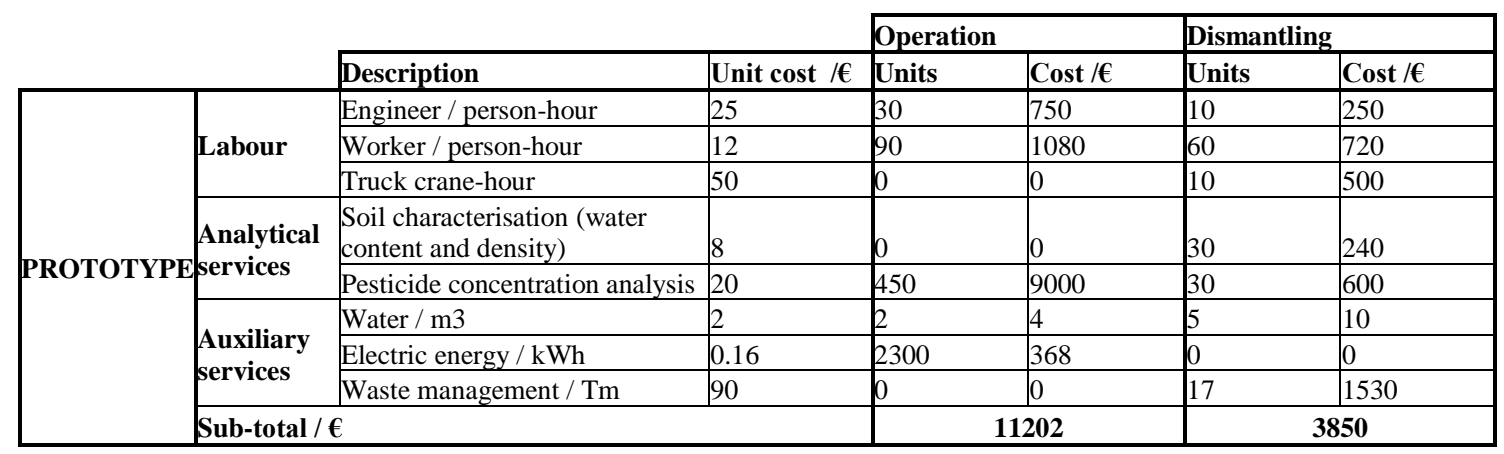

